\title{
Allergies in Orthodontics: From Couses to Management
}

\author{
Dr Raj Kumar Singh,' Dr Nishant Gupta,2 Dr Varun Goyal,3 Dr Gurkeerat Singh,4 Dr Ankit Chaudharis \\ 1.2.3Reader, 4 Professor and Head of the Department, 5 Senior Lecturer, \\ Sudha Rustagi College of Dental Sciences and Research, India
}

Correspondence: Dr Raj Kumar Singh; Email: rajortho2010@gmail.com

\section{ABSTRACT}

\begin{abstract}
Concern about allergic reactions in orthodontic patients has been expressed regularly. Patients undergoing orthodontic treatment with fixed appliances are exposed to various biomaterials. Awareness of reactions that can occur with these dental materials is important to the orthodontist. The aim of this paper is to review the current literature on allergy in orthodontics and the implications of the allergic reaction in the management of patients during orthodontic treatment. Diagnosis and treatment should include a multidisciplinary team. In all instances, the patient's well-being should guide treatment decisions, and general health not just oral health should be the goal.
\end{abstract}

Keywords: Allergic reactions, Orthodontic material, Patch test.

\section{INTRODUCTION}

An allergic response is one in which certain components of the immune system react excessively to a foreign substance. Two key allergic reactions have been described in the literature. Type I hypersensitivity reactions are an immediate antibody mediated allergic response, occurring within minutes or hours after direct skin or mucosal contact with the allergen.' This reaction ranges from contact urticaria to full-blown anaphylaxis with respiratory distress and or hypotension. A delayed hypersensitivity reaction (Type IV), delayed-type hypersensitivity reactions (Type IV allergic reactions) are allergic immune reactions manifesting primarily through $T$ cells (Cellular immunity). ${ }^{2}$ This process has two interrelated, distinct phases. A sensitization phase occurs from the moment the allergen enters the body, is recognized and a response occurs. The elicitation phase occurs after re-exposure to the allergen to the appearance of the full clinical reaction. It presents with diffuse or patchy eczema on the contact area and may be accompanied initially by itching, redness, and vesicle formation.

There is rising concern about the biocompatibility of dental materials; this might be due to a real increase in the occurrence of allergic reactions to the materials or to an increase in awareness of adverse effects from these materials. ${ }^{3}$ Allergy in patients undergoing orthodontic treatment can be seen due to several reasons and these include nickel allergy, allergy to the acrylic resins that are used during treatment, latex products, etc. ${ }^{4}$ Safe and effective practice depends on identifying patients with allergy along with knowledge of materials that can potentially cause them. The Orthodontists should have basic understanding of allergic reactions and should be efficient enough to manage them.

\section{Nickel}

Nickel alloys are widely used in the orthodontic in brackets, wires, bands and other orthodontic accessories. Nickel allergy occurs more frequently than allergy to all other metals combined. ${ }^{5}$ It is estimated that $11 \%$ of all women and $20 \%$ of women between the ages of 16 and 35 years have a sensitivity to nickel..$^{6-8}$ Nickel-induced contact dermatitis is a Type IV delayed hypersensitivity immune response occurring at least 24 hours after exposure.9.10 It has been shown that the level of nickel in saliva and serum increases significantly after the insertion of fixed orthodontic appliances. ${ }^{11}$ Nickel leaching from orthodontic bands, brackets, stainless steel or $\mathrm{Ni}$-Ti archwires has been shown in vitro to occur within the first week and then decline thereafter. ${ }^{12}$ It is suggested that a threshold concentration of approximately 30 ppm of nickel may be sufficient to elicit a cytotoxic response. ${ }^{13}$ Scientific evidence suggests that orthodontic treatment is not associated with increase of $\mathrm{Ni}$ hypersensitivity, unless patients have a history of previous exposure to Ni. People with cutaneous piercing are considered a significant risk 
Table 1: Reading of patch test

\begin{tabular}{|c|c|l|}
\hline Result & Score & \multicolumn{1}{c|}{ Reaction } \\
\hline \multirow{3}{*}{ Negative } & 1 & Absent \\
\cline { 2 - 3 } & 2 & Light erythema \\
\cline { 2 - 3 } & 3 & Erythema \\
\hline \multirow{2}{*}{ Positive } & 4 & Erythema, edema, papules \\
\cline { 2 - 3 } & 5 & Erythema, edema, papules, vesicles \\
\hline
\end{tabular}

factor for Ni allergy. ${ }^{14}$ however, oral exposure to nickel through dental braces prior to ear piercing reduces the risk of developing nickel allergy. ${ }^{15,16}$

Previous allergic response after wearing earrings or a metal watchstrap, appearance of allergy symptoms shortly after the initial insertion of orthodontic components containing Nickel and confined extraoral rash adjacent to headgear studs should raise alarm to clinician concerning nickel allergy.

Signs and symptoms of nickel allergy includes gingivitis, gingival hyperplasia, lip desquamation, burning sensation in the mouth, metallic taste, angular cheilitis, and periodontitis. ${ }^{17,18}$ In chronic cases, the affected mucosa is typically in contact with the causal agent and appears erythematous or hyperkeratotic to ulcerated. ${ }^{19}$ Extraoral manifestations of nickel allergy may have an intraoral origin. ${ }^{20}$ If a nickel allergy is still in question, a diagnosis can be confirmed by a dermatologist by conducting a cutaneous sensitivity test called a patch test (Table 1) using 5\% nickel sulphate in petroleum jelly. ${ }^{21}$

If intra- oral signs and symptoms (Table 2) are present and a diagnosis of nickel hypersensitivity is established, the fixed or removable prosthesis should be replaced with another nickel free alloy. The nickel titanium archwires should be removed and replaced with a stainless steel archwire which is low in nickel content or preferably a titanium molybdenum alloy (TMA) archwire, known as "TMA", which does not contain nickel. ${ }^{22}$ Most patients who develop a reaction to $\mathrm{Ni}-\mathrm{Ti}$ archwires subsequently tolerate stainless steel without a reaction. ${ }^{23}$ Other options include Fiber reinforced composite wires, Gold plated wires, Ion-implanted nickel-titanium archwires or Plastic/Resin-coated nickel-titanium archwires. ${ }^{24}$

Stainless steel brackets are generally considered safe. ${ }^{25}$ However, nickel free alternative brackets to stainless steel include Ceramic brackets produced using polycrystalline alumina, single crystal sapphire, and zirconia, Polycarbonate brackets, Titanium brackets and Gold plated brackets and plastic brackets in selected cases Fixed appliances may be substituted with plastic aligners. Extra-oral metal components, including metal studs in headgear, are of greatest concern due to greater sensitivity of skin. Plastic coated headgear studs may be a better alternative for such patients.

\section{Latex}

Natural rubber (Latex) is a milky juice obtained from rubber tree, Hevea Brasiliensis. There has been increase in allergic reactions to natural rubber latex (NRL) over the past two decades due to increased in the use of latex based gloves as universal precaution measures. Jacobsen and Hensten Pettersen found that, from 1998 to 2000 , there had been a ten-fold increase in reported reactions to NRL during orthodontic treatment. ${ }^{26} \mathrm{Natural}$ rubber latex is found in gloves, intra- and extra-oral elastics, separators, elastomeric modules, elastomeric power chain, polishing rubber cups, band removers. The allergic compounds from natural latex include chemical substances associated to vulcanization, such as residual proteins and chemical substances from powder or talc.

With latex both type I and type IV hypersensitivity reactions can occur. The prevalence of potential type I hypersensitivity to latex is lower than $1 \%$ in the general population and between 6-12\% among dental professionals. ${ }^{27}$ Immediate (Type I) IgE Antibody mediated response to NRL usually occurs within 5-60 minutes of contact with allergen. Severe

Table 2: Signs and symptoms of Nickel allergy 
Table 3: Examples of NRL-free products for use in orthodontics (This table is not exhaustive, and manufacturing processes may change. It is prudent to check with the manufacturer that their products are NRL free)

Intra-oral

Inter-arch elastics

Inter-arch elastics

Intra-arch elastics

\begin{tabular}{|l}
\hline Headgear \\
\hline Separators \\
\hline
\end{tabular}

\section{Self-ligating brackets}

Band remover

Polishing brush/cup

Gloves
Nickel titanium springs

\section{Extra-ora}

GAC (www.gacintl.com): NRL-Free Elastics; Leone (www.leone.it); Dentaurum (info@dentaurum. de): intra-oral elastics

3M Unitek (3M.com): Alastic range of power chain and modules; Dentaurum Dentalastics: plastic ligatures, ligature chain, rotation wedges, 'Personal' coloured modules, Elasto-Force plastic chain; TP Orthodontics (tportho@tportho.com): ligatures, e-links, e-chain

TP Orthodontics: headgear components; 3M Unitek: headgear components, except lining in chin cup which does contain NRL

TP Orthodontics: self-locking separator springs, sep-a-rings; Dentaurum Dentalastics: separators

Damon (www.ormco.com); Speed (www.speedsystem.com); Innovation (GAC); SmartClip (3M Unitek)

GAC; Leone; 3M Unitek; Dentaurum

3M Unitek; TP Orthodontics

Contra petite Web disposable (www.youngdental.com)

Kimberly-Clark (www.kchealthcare.com): Safeskin Purple Nitrile; Bodyguards Nitrile Gloves

(www.medisavers.co.uk); Schottlander (www.schottlander.co.uk): NRL-Free Nitrile; Regent (www.regentmedical.com): Biogel Skinsense PI

Masks without NRL ties systemic reactions, involving the skin, airways and/ or cardiovascular systems, have been reported after cutaneous and respiratory exposure. ${ }^{28}$ More than 10 deaths have been attributed to latex anaphylaxis. ${ }^{29}$ It is also known to cause Allergic contact dermatitis. Contact dermatitis is a $\mathrm{T}$ cell mediated, delayed hypersensitivity (Type IV) reaction. The allergens usually responsible for triggering the allergic reaction are the chemical accelerators like thiurams, carbamates and benzothiazoles that are used in the glovemanufacturing process. ${ }^{28}$ Allergic contact dermatitis can result in an eczematous rash that is typically pruritic. If the mucosa is involved, it may swell, become erythematous or develop small vesicles. patient may also complain of a burning or itching sensation in the affected area. ${ }^{30,31}$ The prevalence of NRL allergy has been reported as being less than $1 \%$ in the general population, $5-15 \%$ in HCWs and $24-60 \%$ in patients with spina bifida.'

Definitive diagnosis should be based on the medical history, and a positive skin reaction to specific chemicals present in natural rubber latex. Confirmation of latex allergy should be obtained by doing latex epicutaneous skin test using natural latex, to determine the presence of circulating antibodies to latex. It seems prudent that when treating patients with clinical and immunological evidence of NRL allergy, contact with potential allergens should be avoided. Patient should be managed in a 'latex-screened' environment and should be monitor every appointment for any signs of adverse reactions.

There are a number of latex free alternatives to commonly used orthodontic materials (Table 3). In the latex sensitive patient, steel ligatures or self ligating brackets may be preferred. Elastomeric separators can be replaced with self-locking separating springs. ${ }^{32}$ Synthetic non-latex gloves made from nitrile, polychloroprene, elastyren and vinyl, are readily available for clinical use. NRL-free elastics are available but they showed greater hysteresis than NRL elastics i.e. $40 \%$ force decay as opposed to $25 \%$ over 24 hours. ${ }^{33}$ Although NRL-free elastics do not perform as well as NRL elastics in laboratory studies, it is unlikely that the relatively small mechanical differences in force decay would have a clinically significant effect.

\section{Acrylic Resin}

Acrylic resins are widely used in dentistry, especially in prosthodontics and orthodontics. It has been reported to occasionally induce an allergic hypersensitivity reaction when used as a denture base or as a restorative material. Acrylic resins based on methylmethacrylate can produce type IV hypersensitivity reactions, which happen after re-exposing a subject to the allergen. ${ }^{34}$ Nealey and Del Rio ${ }^{35}$ described stomatitis venenata, a contact allergy caused by a prosthesis constructed with self cure acrylic resin. Many authors agree that residual monomer leaching into the oral environment is a main cause of allergic reactions. The residual monomer contents are usually about $1.5 \%$ to $4.5 \%$ in self-curing acrylic resins and about $0.3 \%$ in heat-curing resins. ${ }^{36}$

Generally, allergic reactions to acrylic are local manifestations, but there are different clinical presentations like labial edema, ${ }^{37}$ erythema delineating 


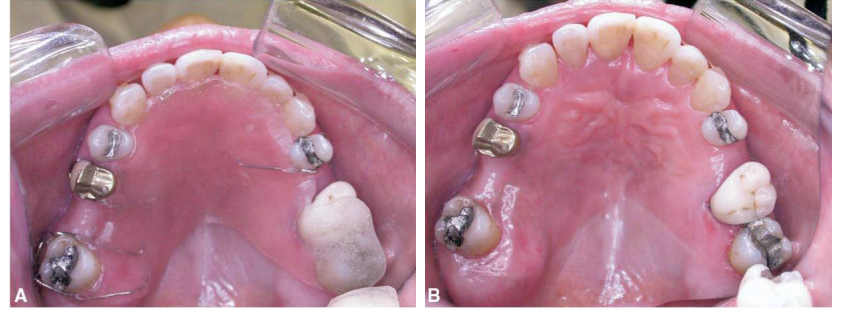

Figure 1: A-Acrylic retainer in place; B-Erythema produced due to allergic reaction of retainer in palate.

the contact area, Burning sensations and chronic urticaria. $^{38}$ Although it is widely used, the orthodontic literature contains little information about allergic reactions to this material.Tatiana Siqueira Gonçalves et al in 2006 reported a case of allergy cause by a removable retainer constructed of clear selfcuring methyl methacrylate acrylic resin (Figure 01). Continued use of acrylic appliance even after seeing the initial intraoral manifestation may also lead to gum hypertrophy in the adjoining area(Figure 02). Although reactions to this kind of allergen are rare, ${ }^{39}$ awareness of local and systemic manifestations is important in orthodontic practice when a patient's general health is concerned. Owing to the frequent contact with, methacrlate resin Dental Health Care Workers are at increased risk of developing allergy. Kerosvo et al in 2000 conducted a survey on occupational problem among Finnish population in relation to orthodontics. They concluded that methacrylate and latex gloves were the two most commonly reported cause of hypersensitivity among clinician's. The adverse effects of acrylics were attributed both to the monomer during handling process of the material and to the acrylic dust generated during grinding of acrylic appiliance..$^{40}$ Suspicious changes should be investigated by a dermatologist and, whenever possible, confirmed by patch test. When a patient is hypersensitive, removal of the etiologic agent is always called for. A skin patch test for the acrylic resin, is recommended Overcoming allergic reactions in denture patients sensitized by methylmethacrylate might require, other substitute to methylmethacrylate include covering the prosthesis with light polymerized methyl methacrylate, covering it with ultraviolet polymerized urethane

acrylate, covering it with ultraviolet polymerized methacrylate, and using polycarbonate prosthesis. ${ }^{41}$ Instead of methacrylate resin Clear aligner can be used as a retainer to avoid the allergic reactions. A bonded lingual retainer can be used instead of acrylic based removable retainer.
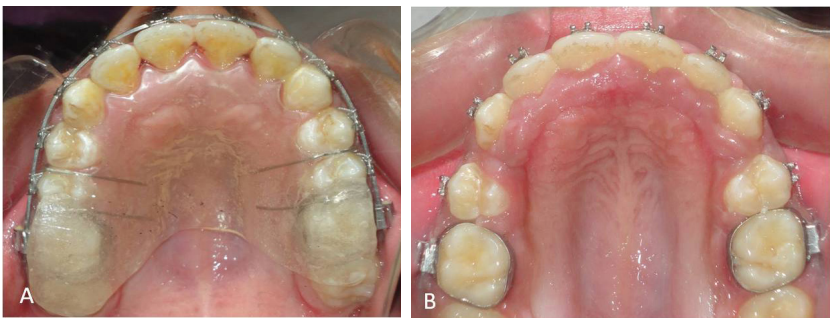

Figure 2: A-Acrylic appliance in maxillary arch in place: B-Erythema and hypertrophy produced due to allergic reaction and continued use of appliance in palate.

\section{Other Materials}

Chromium is the second most frequent metal to cause contact dermatitis. ${ }^{42}$ Luciane et al in 2004 in their study demonstrated high sensitivity rates to chromium, in orthodontic patients (21.1\%), though greater tendency to positivity was found in male patients as compare to female. ${ }^{43}$ The chances of an adverse reaction to chromium found in dental materials, appears to be rare. ${ }^{44}$ Similarly documented cases of platinum hypersensitivity are even rarer than chromium allergy. ${ }^{45}$ Resin composite materials could be an etiologic factor in the development of lichenoid reactions in the oral mucosa. ${ }^{46}$ The pathogenic mechanism may be related to contact allergy to formaldehyde formed in resin composite restorations. Though the chances of an adverse reaction to these dental materials, appears to be remote clinicians should nevertheless always be on the alert.

\section{CONCLUSION}

Safe and effective practice in Orthodontics depends on identifying patients with allergy along with knowledge of materials that can potentially cause them. It is important for a clinician to not only know the physical and mechanical properties of the materials being used, but also of the biologic compatibility of the material. Knowledge of alternatives to allergy causing materials is also of prime importance in efficient management of patients in routine clinical practice. A detailed history, with special attention to previous allergic reactions, is the main prognostic factor to avoid allergic reactions during orthodontic therapy. The clinician should be mindful of these reactions during the course of orthodontic treatment, and should know to diagnose and subsequent action to be taken in treatment plan. 


\section{REFERENCES}

1. Poley GE Jr, Slater JE. Latex allergy. J Allergy Clin Immunol 2000; 105: 1054-62.

2. Andrijana Bakula, Liborija Lugović-Mihić, Mirna Šitum, Juraj Turčin and Ana Šinković. Contact allergy in the mouth: diversity of clinical presentations and diagnosis of common allergens relevant to dental practice. Acta Clin Croat 201 1; 50:553-561.

3. Stenman E, Bergman M. Hypersensitivity reactions to dental materials in a referred group of patients. Scand J Dent Res 1989; 97:76-83.

4. Hensten-Pettersen A, Jacobsen N. Disintegration of orthodontic appliances in vivo. In: Eliades G, Eliades T, Brantley WA, Watts DC, editors. In Vivo Aging of Dental Biomaterials. Chicago: Quintessence; 2003, p. 290-296.

5. Lowey M N. Allergic contact dermatitis associated with the use of Interlandi headgear in a patient with a history of atopy. Br Dent J 1993 ; 17: 67-72.

6. Nielson N H, Menne T. Allergic contact sensitization in an unselected Danish population: the Glostrup allergy study, Denmark. Acta Derm Venereol 1992; 72: 456-460.

7. Nielson N H, Menne T. Nickel sensitization and ear piercing in an unselected Danish population. Contact Dermatitis 1993; 29: 16-21

8. Menne T. Prevention of nickel allergy by regulation of specific exposures. Ann Clin Lab Sci 1996; 26: $133-138$.

9. Al-Tawil N, Marcusson J, Moller E. Lymphocyte transformation test in patients with nickel sensitivity: an aid to diagnosis. Acta Derm Venereol. 1981;61:511-515.

10. Van Loon LA, van Elsas PW, Bos JD, Ten Harkel-Hagenaar HC, Krieg SR, Davidson CL.T-lymphocyte and Langerhans cell distribution in normal and allergically-induced oral mucosa in contact with nickel-containing dental alloys. J Oral Pathol. 1988;17:129-137.

11. Agaoglu G, Arun T, Izgü B, Yarat A. Nickel and chromium levels in the saliva and serum of patients with fixed orthodontic appliances. Angle Orthod 2001; 71: 375-79.

12. Barrett RD, Bishara SE, Quinn YK. Biodegradation of orthodontic appliances. Part 1: biodegradation of nickel and chromium in vitro. Am J Orthod Dentofac Orthop 1993; 103: 8-14.

13. Bour H, Nicolas JF, Garrigue JL, Demidem A, Schmitt D. Establishment of nickel-specific T cell lines from patients with allergic contact dermatitis: Comparison of three different protocols. Clin Immunol Immunopathol 1994: 73: 142-5.

14. Thyssen JP, Linneberg A, Menne T, Johansen JD. The epidemiology of contact allergy in the general population-prevalence and main findings. Contact Dermatitis 2007;57:287-99.

15. Mortz CG, Lauritsen JM, Bindslev-Jensen C, Andeersen KE. Nickel sensitization in adolescents and association with ear piercing, use of dental braces and hand eczema. Acta Derm Venereol Suppl (Stockh).2002;82:359-364

16. Van Hoogstraten IMW, Andersen KE, von Blomberg BME, et al. Reduced prevalence of nickel allergy upon oral nickel contact at an early age. Clin Exp Immunol. 1991;85:441-445.

17. Staerkjaer L, Menne T. Nickel allergy and orthodontic treatment. Eur J Orthod. 1990;12:284-289.

18. Bishara SE, Barrett RD, Selim MI. Biodegradation of orthodontic appliances. Part II. Changes in the blood level of nickel. Am J Orthod Dentofacial Orthop. 1993;103:115-119.

19. Genelhu MC, Marigo M, Alves-Oliveira LF, Malaquias LC, Gomez RS. Characterisation of nickel induced allergic contact stomatitis associated with fixed orthodontic appliances. Am J Orthod Dentofacial Orthop 2005;128:378-81.

20. Schultz J C, Connelly E, Glesne L, Warshaw E M Cutaneous and oral eruption from oral exposure to nickel in dental braces. Dermatitis 2004; 15: 154-157.

21. Menne T, Brandup F, Thestrup-Pedersen K, Veien N K et al. Patch test reactivity to nickel alloys. Contact Dermatitis 1987; 16: 255-259.

22. Kim H, Johnson J.Corrosion of stainless steel, nickeltitanium, coated nickel-titanium and titanium orthodontic wire. Angel Orthod 1999; 69:39-44.

23. Toms AP. The corrosion of orthodontic wire. Eur J orthod 1988; 10:87-97.

24. Kim H, Johnson J. Corrosion of stainless steel, nickeltitanium, coated nickel-titanium, and titanium orthodontic wire. Angle Orthod 1999; 69: $39-44$.

25. G. Rahilly, N. Price Current Products and Practice Nickel allergy and orthodontics Journal of Orthodontics, Vol. 30, $2003,171-174$.

26. Jacobsen N, Hensten-Pettersen A. Changes in occupational health problems and adverse patient reactions in orthodontics from 1987 to 2000. Eur J Orthod 2003; 25: 591-98.

27. Patel A, Burden D J, Sandler J. Medical disorders and orthodontics Journal of Orthodontics, Vol. 36, 2009, 1-21.

28. M. A. Hain, L. P. Longman, E. A. Field, J. E. Harrison. Natural rubber latex allergy: implications for the orthodontist Journal of Orthodontics, Vol. 34, 2007, 6-11.

29. DW Gelfand Am J Roentgenol. Barium enemas, latex balloons, and anaphylacticreactions. 1991; 156(1):1-2.

30. Neiburger EJ. A case of possible latex allergy. J Clin Orthod 1991; 25: 559-60.

31. Everett FG, Hice TL. Contact stomatitis resulting from the use of orthodontic rubber elastics: report of case. J Am Dent Assoc 1974; 88: 1030-31.

32. Hain MA, Longman LP, Field E, Harrison J. Natural rubber latex allergy:implications for the orthodontist. J Orthod 2007; 34: 6-1 1.

33. Russell KA, Milne AD, Khanna RA, Lee JM. In vitro assessment of the mechanical properties of latex and non latex orthodontic elastics. Am J Orthod Dentofacial Orthop 2004; 126: 65-70.

34. Devlin H, Watts DC.Acrylic "allergy"? Br Dent J 1984; 157: 272-5.

35. Nealey ET, Del Rio CE. Stomatitis venenata: reaction of a patient to acrylic resin. J Prosthet Dent 1969;21:480-4.

36. Hugget R, Brooks B, Bates JF. The effect of different curing cycles on levels of residual monomer in acrylic resin denture base materials. Quintessence Dent Technol 1984:8:365-70. 
37. Ruiz-Genao DP, Moreno De Vega MJ, Sanchez Perez J, Garcia- Diez A. Labial edema due to an acrylic dental prosthesis. Contact Dermatitis 2003;48:273-4.

38. Lunder T, Rogl-Butina M. Chronic urticaria from an acrylic dental prosthesis. Contact Dermatitis 2000;43:232-3.

39. Kanerva L, Rantanen T, Aalto-Korte K, Estlander T, Hannuksela M, Harvima RJ, et al. A multicenter study of patch test reactions with dental screening series. Am J Contact Dermat 2001;12:83-7.

40. Kerosuo, H Kerosuo, L Kanerva occupation-related health complaints among general dental dental practitioners, orthodontists, and office employees. Acta Odontol scand $2000 ; 58: 207-212$.

41. Kanerva L, Tarvainen K, Jolanki R, Estlander T. Successful coating of an allergenic acrylate-based dental prosthesis. Am J Contact Dermat 1995; 6:24-7.

42. Park HY, Shearer TR. In vitro release of nickel and chromium from simulated orthodontic appliances. Am J Orthod Dentofacial Orthop 1983;84:156-9.

43. Luciane M. Menezes, Luis C. Campos, Catia C. Quinta and Ana M. Bolognese Hypersensitivity to metals in orthodontics Am J Orthod Dentofacial Orthop 2004;126:58-64.

44. Burrows D. Hypetsensitivity to mercury, nickel and chromium in relation to dental materials. Int Dent J 1986.36:30-34.

45. William A. Wiltshire,Maryna R. Ferreira and At J. Ligthelm. Allergies to dental materials (Quintessence Int. 1996:27:513-520.

46. Lind PO Oral lichenoid reactions retalcd to composite reslorations. Preliminary report. Acta Odontol. Scatid.1988:46:63-65. 